\title{
Utility of Stewart's Approach to Diagnose Missed Complex Acid-Base Disorders as Compared to Bicarbonate-anion Gap-based Methodology in Critically Ill Patients: An Observational Study
}

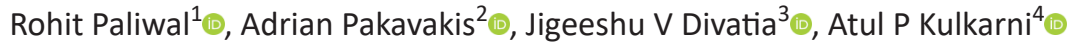

\begin{abstract}
Background: Traditional arterial blood gas (ABG) analysis may miss out on some metabolic acid-base disorders. We prospectively compared Stewart's approach in critically ill patients to traditional bicarbonate-anion gap-based methods (with and without correction for albumin) to diagnose acid-base disorders.

Patients and methods: Five hundred ABG samples from medical or surgical patients in the ICU were analyzed with traditional bicarbonate-anion gap-based methodology with and without correction for albumin and Stewart's biochemical approach. The primary outcome identification of additional metabolic disorders diagnosed with Stewart's approach in comparison to bicarbonate system-based approaches. We also looked at the correlation between the strong ion gap (SIG) and the albumin-corrected anion gap (acAnion Gap).

Results: Stewart's approach detected missed metabolic disorders in 58 (11.6\%) blood gas results reported as "within normal limits" with the bicarbonate-uncorrected anion gap approach. In 50 (10\%) of these ABGs, the acAnion Gap approach was able to diagnose the missed metabolic disorders. Thus, the albumin-corrected anion gap method had a similar diagnostic performance to Stewart's approach, as it missed additional disorders in only eight (1.6\%) blood gases.

Conclusion: In this study, we found that the acAnion Gap approach was similar in diagnostic performance to Stewart's approach. We feel that the corrected anion gap approach can be safely used if a ready calculator for Stewart's approach is not available.

Keywords: Albumin-corrected anion gap, Anion gap, Bicarbonate-based ABG analysis, Stewart's approach, Strong ion difference, Unidentified strong ions.

Indian Journal of Critical Care Medicine (2022): 10.5005/jp-journals-10071-24077
\end{abstract}

\section{INTRODUCTION}

In critically ill intensive care patients, severe acid-base disturbances are the norm rather than an exception. The most commonly used approach to acid-base analysis at the bedside is based on the bicarbonate-anion gap system. It is also widely used in most blood gas analyzers.

This approach however is not perfect and has been shown to miss metabolic acid-base disorders in critically ill patients. ${ }^{1}$ In the bicarbonate system, the calculation of the anion gap (AG) contributes additional diagnostic information on unmeasured anions, however, it is known that hypoalbuminemia reduces its usefulness. ${ }^{2}$ Hence, it is recommended to adjust the anion gap to albumin levels ( $\left.A G_{\text {corrected }}\right)$. ${ }^{3,4}$

Stewart's approach to acid-base chemistry applies basic physicochemical principles of aqueous solutions to blood. It is based on fundamental laws of electroneutrality and principles of chemical equilibrium (laws of conservation of mass and laws of mass action). ${ }^{5}$ It takes into consideration the role of all the buffer molecules (including hemoglobin) contributing to acid-base equilibrium in the body. Since it accounts for all biochemical elements present in the blood, we considered Stewart's approach to be the gold standard for this study.

The negative charge of plasma proteins, mainly albumin, and other weak acids, participate in the electroneutrality of plasma and contribute to the acid-base status. ${ }^{6,7}$ Albumin is the main contributor of total nonvolatile weak acid in plasma's chemical
1,2Department of Intensive Care Medicine, Monash Medical Center, Clayton, Victoria, Australia

${ }^{3,4}$ Department of Anaesthesia, Critical Care and Pain, Tata Memorial Hospital, Homi Bhabha National Institute, Mumbai, Maharashtra, India

Corresponding Author: Atul P Kulkarni, Department of Anaesthesia, Critical Care and Pain, Tata Memorial Hospital, Homi Bhabha National Institute, Mumbai, Maharashtra, India, Phone: +91 9869077526, e-mail: kaivalyaak@yahoo.co.in

How to cite this article: Paliwal R, Pakavakis A, Divatia JV, Kulkarni AP. Utility of Stewart's Approach to Diagnose Missed Complex Acid-Base Disorders as Compared to Bicarbonate-anion Gap-based Methodology in Critically III Patients: An Observational Study. Indian J Crit Care Med 2022;26(1):23-32.

Source of support: Nil

Conflict of interest: None

equilibrium, since serum globulins do not carry a significant net electric charge.

Most critically ill patients have low albumin, and this creates an alkalinizing effect which hides excess of unmeasured anions (lactate or ketoacids), confounding the acid-base status of the plasma, thus affecting the interpretation, unless we correct the anion gap for low albumin. ${ }^{8}$

() The Author(s). 2022 Open Access This article is distributed under the terms of the Creative Commons Attribution 4.0 International License (https://creativecommons. org/licenses/by-nc/4.0/), which permits unrestricted use, distribution, and non-commercial reproduction in any medium, provided you give appropriate credit to the original author(s) and the source, provide a link to the Creative Commons license, and indicate if changes were made. The Creative Commons Public Domain Dedication waiver (http://creativecommons.org/publicdomain/zero/1.0/) applies to the data made available in this article, unless otherwise stated. 
The other problem with the bicarbonate approach is that phosphate, which serves as a nonbicarbonate buffer, is not accounted for. ${ }^{6}$ In critically ill cancer patients, phosphate concentrations are significantly increased in patients with hematological malignancies with tumor lysis syndrome or those with severe renal failure. Similarly, increased globulin levels in patients with plasma cell disorders, ranging from solitary plasmacytoma to multiple myeloma or in patients on high doses of polymyxin antibiotics, affect the interpretation of acid-base balance. ${ }^{9}$ Albumin and phosphate concentrations are accounted for in Stewart's approach, unlike the traditional uncorrected bicarbonate approach.

We hypothesized that owing to these omissions; important metabolic acid-base abnormalities can be missed with the traditional approach, in critically ill patients..$^{10-13}$ We, therefore, conducted this study to see if Stewart's approach was better than the bicarbonate system-based approaches, in the ability to diagnose disorders in arterial blood gases (ABGs) labeled as normal, after analyzing them with both traditional approaches, in critically ill patients.

\section{Patients and Methods}

This prospective observational study with a review of patient charts and investigations was carried out in the intensive care unit (ICU) of a tertiary referral cancer center. The institutional review board approval was obtained, which waived off written informed consent. Data from five hundred ABG samples were randomly collected from patients admitted to our mixed medical-surgical ICU admissions over a period of 3 months (May 1, 2013-July 31, 2013). The patient's demographic data, medical record number, presenting pathology, acute medical issues, and comorbidities were recorded. For the purpose of the study, only the data from the ABG collected simultaneously with biochemical investigations was analyzed. The values from these results were used as inputs for Stewart's calculator.

The $\mathrm{pH}, \mathrm{PO}_{2}$, and $\mathrm{PCO}_{2}$ values were measured with the blood gas analyzer (radiometer: COBAS B221, ROSCHE diagnostics). Samples of separated plasma were analyzed for $\mathrm{Na}^{+}$and $\mathrm{K}^{+}, \mathrm{Ca}^{2+}$ and $\mathrm{Mg}^{2+}$, $\mathrm{Cl}^{-}$, inorganic phosphate, total protein, serum albumin, urea, uric acid, creatinine (DECMAN COULTER AU 2700), and hemoglobin (SIEMENS ADVIA 2120).

\section{Bicarbonate Approach}

Using the measured $\mathrm{pH}$ and $\mathrm{PCO}_{2}$, the $\mathrm{HCO}_{3}{ }^{-}$was calculated by the blood gas analyzer using the Henderson-Hasselbalch equation. A sequential stepwise approach to acid-base analysis was performed; firstly for anion gap without correction for albumin, and then with anion gap corrected for albumin. Delta gap and delta ratio were calculated for all blood gas samples to identify mixed disturbances. The results were then compared with Stewart's approach (see Supplementary Material).

\section{Stewart's Approach}

Stewart's approach calculations were performed by using a validated, downloaded spreadsheet calculator, Acid-Base Calculator V10.8.xls from the website www.acid-base.org (see Appendix). The calculator accepts laboratory data $\left(\mathrm{pH}, \mathrm{PCO}_{2}\right.$, $[\mathrm{Na}]^{+1},[\mathrm{~K}]^{+1},[\mathrm{Cl}]^{-1}$, protein, phosphate, hemoglobin, urea, uric acid, sulfate, and other ionic concentrations) as inputs and displays a report which quantifies the three independent parameters that are known to control acidity, i.e., $\mathrm{SID}, \mathrm{A}_{\mathrm{TOT}}$, and $\mathrm{PaCO}_{2}$ (see Supplementary Material).

The pro forma used for data collection can be seen in Table 1. Normal values of parameters and reference ranges taken for analysis are mentioned in Table 2. Table 3 shows the parameters and their range in the study sample. The diagnoses arrived at with traditional approaches (anion gap without and with correction for albumin) were then compared with the results of Stewart's approach.

The blood gases labeled as within normal limits by the bicarbonate-uncorrected anion gap methodology were evaluated for any missed disorders picked up by the corrected anion gap and Stewart's approach. The primary outcome for the study was the proportion of additional disorders diagnosed using Stewart's approach and the corrected anion gap approach.

A proportion of blood gases with hyperlactatemia (lactate levels $>2 \mathrm{mmol} / \mathrm{L}$ ), hypoalbuminemia (albumin $<34 \mathrm{~g} / \mathrm{L}$ ), and metabolic alkalosis secondary to hypoalbuminemia (reduced $\mathrm{A}_{\text {TOT }}$ with normal SID), was calculated.

Table 1: Data collection pro forma

\begin{tabular}{|c|}
\hline Patient Reg. No./age/sex \\
\hline Diagnosis/comorbidities \\
\hline $\mathrm{pH} /\left[\mathrm{HCO}_{3}{ }^{-}\right](\mathrm{mmol} / \mathrm{L}) /$ base excess $(\mathrm{mmol} / \mathrm{L})$ \\
\hline $\mathrm{PCO}_{2}(\mathrm{kPa}) \mathrm{PCO}_{2}(\mathrm{~mm} \mathrm{Hg}) \mathrm{PO}_{2}(\mathrm{kPa}) \mathrm{PO}_{2}(\mathrm{~mm} \mathrm{Hg})$ \\
\hline Base excess, [Lactate $]$ (mmol/L), [Glucose] (mg/dL) \\
\hline$\left[\mathrm{Na}^{+}\right](\mathrm{mmol} / \mathrm{L}),\left[\mathrm{K}^{+}\right](\mathrm{mmol} / \mathrm{L}),\left[\mathrm{Cl}^{-}\right](\mathrm{mmol} / \mathrm{L})$ \\
\hline$\left[\mathrm{Ca}^{2+}\right](\mathrm{mmol} / \mathrm{L})\left(\right.$ total), $\left[\mathrm{Mg}^{2+}\right](\mathrm{mmol} / \mathrm{L})$ \\
\hline$\left[\right.$ Phosphate $\left.^{-}\right](\mathrm{mmol} / \mathrm{L})\left[\right.$ Sulphate $\left.{ }^{2-}\right](\mathrm{mmol} / \mathrm{L})$ \\
\hline [Total protein] (g/L) [Albumin] (g/L) \\
\hline $\begin{array}{l}\text { [Uric acid] (mmol/L) [Creatinine] (mg/dL) [Urea] (mg/dL) } \\
{[\mathrm{Hb}](\mathrm{g} / \mathrm{L})}\end{array}$ \\
\hline Anion gap \\
\hline Albumin-corrected anion gap \\
\hline Delta gap/delta gap (Alb corrected) \\
\hline Delta ratio/delta ratio (albumin-corrected) \\
\hline $\mathrm{SIG} / \mathrm{SID} / \mathrm{A}_{\mathrm{TOT}}$ \\
\hline Results \\
\hline Traditional approach \\
\hline Traditional approach corrected for albumin \\
\hline Stewart's approach \\
\hline
\end{tabular}

This pro forma was used to collect data and enter the analysis of blood gases with all three approaches

Table 2: Normal reference ranges for ABG analysis

\begin{tabular}{lc}
\hline Parameter & Reference range \\
\hline $\mathrm{pH}$ & $7.4 \pm 0.05$ \\
$\mathrm{HCO}_{3}$ & $24 \pm 2 \mathrm{mEq} / \mathrm{L}$ \\
$\mathrm{PaCO}_{2}$ & $40 \pm 5 \mathrm{~mm} \mathrm{Hg}$ \\
$\mathrm{SID}$ (strong ion difference) & $35 \pm 2 \mathrm{mEq} / \mathrm{L}$ \\
Anion GAP & $12 \pm 2 \mathrm{mEq} / \mathrm{L}$ \\
SIG/NUI (net unmeasured ions) & $\pm 3 \mathrm{mEq} / \mathrm{L}$ \\
Albumin & $40 \pm 6 \mathrm{~g} / \mathrm{L}$ \\
$\mathrm{A}_{\mathrm{TOT}}$ (weak acid concentration) & $17 \pm 2 \mathrm{mEq} / \mathrm{L}$ \\
\hline
\end{tabular}


Table 3: Parameters with their range in the study sample

\begin{tabular}{|c|c|}
\hline Parameters & Range \\
\hline $\mathrm{pH}$ & $7.2 \pm 0.37$ \\
\hline $\mathrm{PCO}_{2}(\mathrm{~mm} \mathrm{Hg})$ & $63.4 \pm 51$ \\
\hline $\mathrm{PO}_{2}(\mathrm{~mm} \mathrm{Hg})$ & $245 \pm 210$ \\
\hline $\mathrm{HCO}_{3}^{-}(\mathrm{mmol} / \mathrm{L})$ & $26 \pm 16.6$ \\
\hline Base excess (mmol/L) & $1.1 \pm 18$ \\
\hline Lactate $(\mathrm{mmol} / \mathrm{L})$ & $8.1 \pm 7.8$ \\
\hline Glucose (mg/dL) & $20 \pm 19$ \\
\hline $\mathrm{Na}^{+}(\mathrm{mmol} / \mathrm{L})$ & $148 \pm 12$ \\
\hline $\mathrm{K}^{+}(\mathrm{mmol} / \mathrm{L})$ & $5.2 \pm 3.9$ \\
\hline $\mathrm{Mg}^{++}(\mathrm{mmol} / \mathrm{L})$ & $3.1 \pm 2.8$ \\
\hline $\mathrm{Cl}^{-}(\mathrm{mmol} / \mathrm{L})$ & $104.5 \pm 24.5$ \\
\hline Calcium $^{++}(\mathrm{mmol} / \mathrm{L})$ & $2.9 \pm 1.7$ \\
\hline Phosphate (mmol/L) & $2.6 \pm 2.4$ \\
\hline Total protein (g/L) & $54 \pm 30$ \\
\hline Albumin (g/L) & $29 \pm 20$ \\
\hline Uric acid (mmol/L) & $8 \pm 7.9$ \\
\hline Creatinine $(\mu \mathrm{mol} / \mathrm{L})$ & $435 \pm 425$ \\
\hline Urea $(\mathrm{mmol} / \mathrm{L})$ & $55 \pm 54$ \\
\hline $\mathrm{Hb}(\mathrm{g} / \mathrm{L})$ & $105 \pm 70$ \\
\hline Anion gap (mmol/L) & $15 \pm 21$ \\
\hline Albumin-corrected anion gap (mmol/L) & $20.5 \pm 19.5$ \\
\hline Delta gap (mmol/L) & $3 \pm 21$ \\
\hline Delta gap (albumin-corrected) & $7 \pm 21$ \\
\hline Delta ratio & $-9 \pm 50$ \\
\hline Delta ratio (albumin-corrected) & $7 \pm 21$ \\
\hline Strong ion gap $(\mathrm{mEq} / \mathrm{L})$ & $-3 \pm 26$ \\
\hline Strong ion difference $(\mathrm{mEq} / \mathrm{L})$ & $47 \pm 27$ \\
\hline $\mathrm{A}_{\text {TOT }}(\mathrm{mEq} / \mathrm{L})$ & $18 \pm 10$ \\
\hline
\end{tabular}

\section{Statistical Analysis}

We did not perform a formal sample size calculation; since there is scarce data available about how many disorders may be missed with the traditional approaches as applied to ABG analysis and included $500 \mathrm{ABG}$ s as a convenience sample. Statistical analysis was performed with Stata/IC v16 (College Station, TX) software. Linear regression, correlation coefficients, and Bland and Altman analyses were performed between SIG and corrected anion gap to explore the relationship between these variables as they both represent unmeasured ions. ${ }^{14} \mathrm{~A} p$-value of $<0.05$ was taken to be statistically significant for the linear regression.

\section{Results}

In this study, a total of 500 ABG samples were collected from 128 patients. Of these 44 were females (34.4\%) and 84 males (65.6\%). The age ranged from 1.5 to 80 years (mean 42.4 years). There were 80 (61\%) patients with solid organ malignancies, while the remaining (48 patients, 39\%) had hematological malignancies.

Stewart's approach picked up missed metabolic disturbances in 58 (11.6\%) ABG results; which appeared to benormal with the uncorrected anion gap approach, and in 8 (1.6\%) blood gases labeled normal with corrected anion gap approach. The bicarbonate-uncorrected anion gap approach missed metabolic disorders in 10 and $11.6 \%$ of $A B G s$ when compared with either bicarbonate-corrected anion gap or Stewart's approach, respectively (Table 4).
The $95 \%$ limits of agreement between the two parameters, the albumin-corrected AG, and strong ion gap (SIG) were -2.38 to 17.01 with a mean difference of 7.31 (Fig. 1). These wide limits suggest poor agreement. Since the expected difference between these parameters should be 12 (normal AG 12 and SIG 0), these findings suggest that with the recorded data, one could not reliably predict the value of each of these parameters from the other. We also calculated the correlation between the albumin-corrected anion gap (acAnion Gap) and the SIG (Stewart's approach), as they both indicate the presence of unmeasured ions. A correlation was moderate with Pearson's $r=0.51$ and a significant regression coefficient of 0.576 ( $p<0.001)$ (Fig. 2). This suggests that the corrected anion gap and SIG which are measurements of similar entities moved in the same general direction but not perfectly.

Table 4: Summary of acid-base disorders diagnosed by the three approaches

\begin{tabular}{|c|c|}
\hline ABG disorders details & No. of $A B G s$ \\
\hline Number of ABG's with hyperlactatemia ( $>2 \mathrm{mmol} / \mathrm{L}$ ) & $181(36.2 \%)$ \\
\hline $\begin{array}{l}\text { Number of } A B G \text { 's with severe hyperlactatemia } \\
(>5 \mathrm{mmol} / \mathrm{L})\end{array}$ & $31(6.2 \%)$ \\
\hline Number of ABG's with hypoalbuminemia (<34 g/L) & $453(90.6 \%)$ \\
\hline $\begin{array}{l}\text { Number of ABG's with severe hypoalbuminemia } \\
(<20 \mathrm{~g} / \mathrm{L})\end{array}$ & $109(21.8 \%)$ \\
\hline $\begin{array}{l}\text { Number of ABG's with metabolic alkalosis caused by } \\
\text { severe hypoalbuminemia* }\end{array}$ & $12(2.4 \%)$ \\
\hline $\begin{array}{l}\text { ABG disorders missed by uncorrected anion gap } \\
\text { approach in ABGs labeled as normal by corrected } \\
\text { anion gap approach }\end{array}$ & $50(10 \%)$ \\
\hline $\begin{array}{l}\text { ABG disorders missed by uncorrected anion gap } \\
\text { approach, picked up by Stewart's approach }\end{array}$ & $58(11.6 \%)$ \\
\hline $\begin{array}{l}\text { ABG disorders missed by corrected anion gap } \\
\text { approach, picked up by Stewart's approach }\end{array}$ & $8(1.6 \%)$ \\
\hline \multicolumn{2}{|c|}{$\begin{array}{l}\text { "Stewart's approach helped identify and understand metabolic alkalosis } \\
\text { caused by severe hypoalbuminemia. These patients had a positive base } \\
\text { excess and elevated } \mathrm{HCO}_{3}{ }^{-} \text {and did not have an elevated SID or abnormal } \\
\text { sodium concentration, suggesting alkalosis was not due to the presence of a } \\
\text { positivelychargedspeciesorwaterdeficitbut duetoseverehypoproteinemia } \\
\text { being the cause of a reduced } \mathrm{A}_{\text {TOT }}\end{array}$} \\
\hline
\end{tabular}

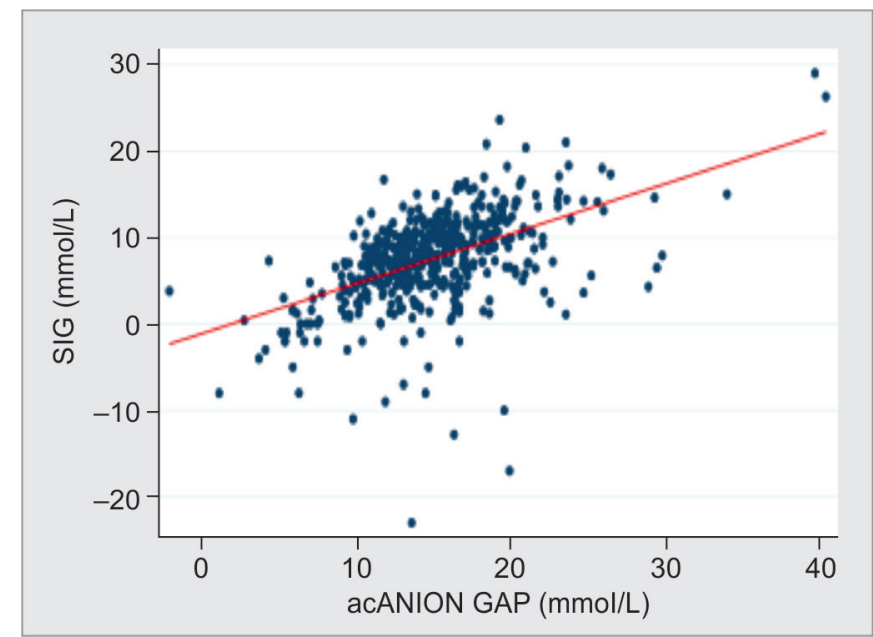

Fig. 1: Linear regression plot between acAnion Gap and SIG 
The base excess of extracellular fluid (BE ECF) indicates the nonrespiratory, i.e., metabolic component in acid-base disorders (normal -2 to $+2 \mathrm{mEq} / \mathrm{L}$ ), while the strong ion difference (SID) indicates the balance between the anions and cations. The normal SID is 0, i.e., the SID is neutralized by unmeasured anions. The $95 \%$ limits of agreement between the base excess and SID were also wide at 33.52-53.99 (mean difference of 43.76), indicating possibly that they cannot be used interchangeably. The correlation, however, was stronger with Pearson's $r=0.69$, and the regression coefficient was $0.712(p<0.001)$ (Figs 3 and 4$)$.

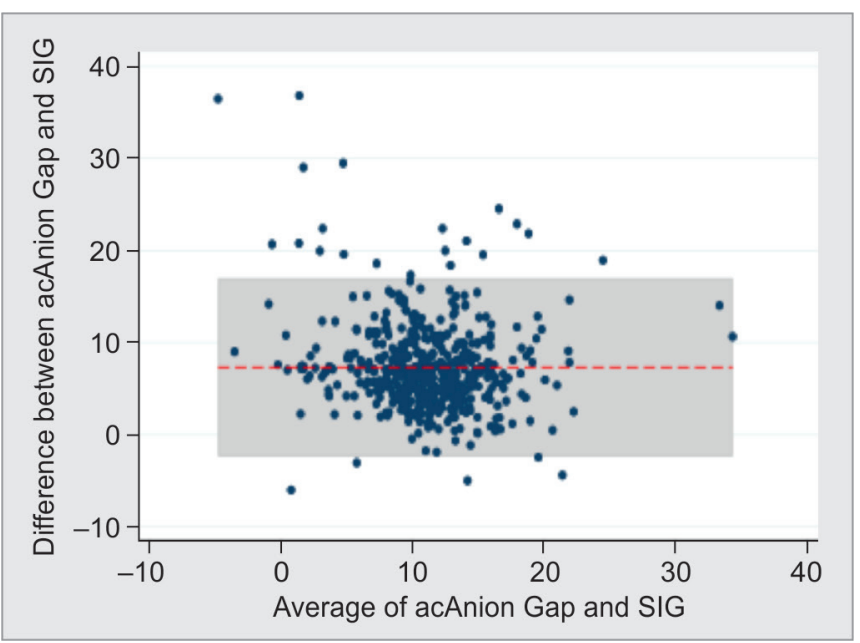

Fig. 2: Bland-Altman plot of acAnion Gap and SIG

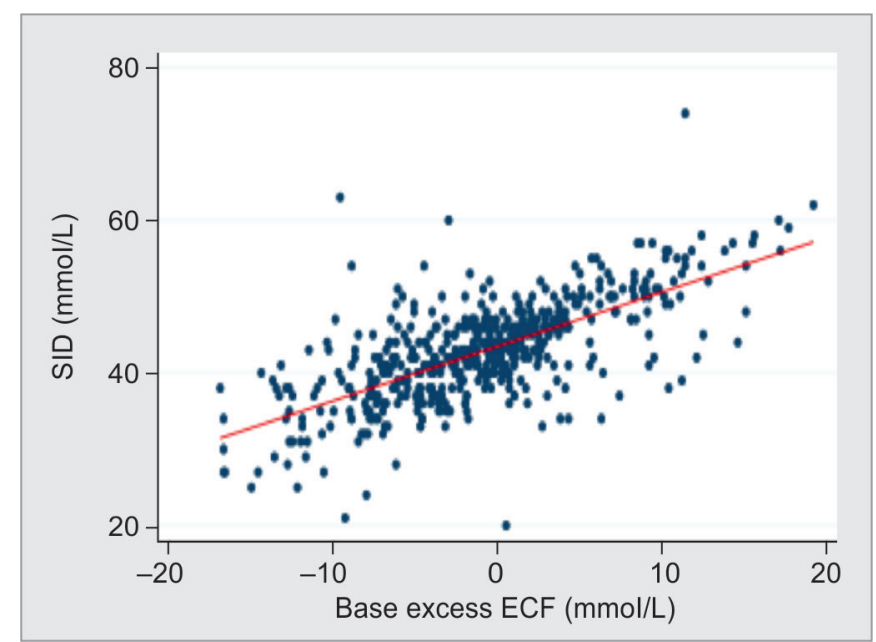

Fig. 3: Linear regression plot between BE ECF against SID

\section{Discussion}

We found that Stewart's approach detected acid-base disorders in complex critically ill patients missed by the uncorrected anion gap bicarbonate method, i.e., in 50 (10\%) 58 blood gas samples, the acAnion Gap approach was able to correctly diagnose the missed metabolic disorders. Hence, Stewart's approach identified additional disorders in only eight (1.6\%) blood gas samples,

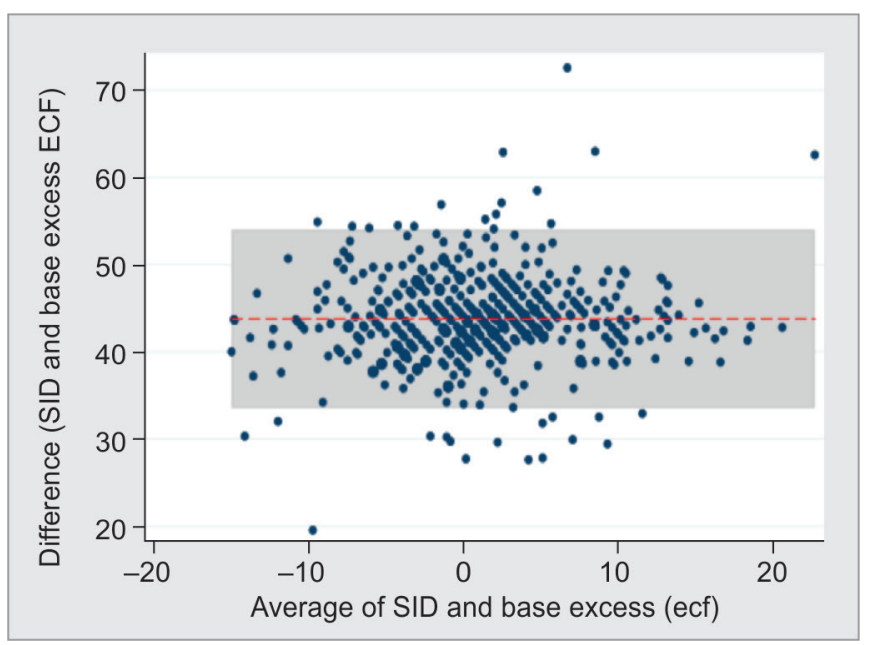

Fig. 4: Bland-Altman plot of BE ECF and SID

when compared to the corrected anion gap approach. Thus, the diagnostic performance of the albumin-corrected anion gap approach was similar to Stewart's approach. McAuliffe suggested that hypoproteinemia (hypoalbuminemia) causes metabolic alkalosis, hiding the metabolic acidosis caused by unmeasured anions if the traditional bicarbonate method is used. Stewart's approach will however lead to correct diagnosis and also the traditional method once we correct the anion gap for low albumin. ${ }^{15}$

Stewart's approach uses actual values of all parameters such as protein, phosphate, chloride, hemoglobin, urea, uric acid, and does not have any compensation rules or formulae. It provides a complete description of the acid-base status of an individual. In our study, Stewart's approach diagnosed extra acid-base disorders in $11.6 \%$ of blood gas samples reported as normal with the uncorrected anion gap approach.

Dubin et al. compared Stewart's approach with the bicarbonate and Base Excess method for evaluating acid-base disorders in 935 critically ill patients. It detected metabolic disorders, such as metabolic acidosis in $14 \%$ of patients who had normal bicarbonate and base excess. However, when the anion gap was corrected for albumin levels, the difference came down to only $1 \%$. This is similar to our findings. ${ }^{10}$ In another study, Fencl et al. compared Stewart's approach with bicarbonate and base excess/base deficit methods in 152 critically ill patients. Of these, $96 \%$ of patients had hypoalbuminemia. They looked at patients who had normal base excess or plasma bicarbonate concentration to see if Stewart's approach could diagnose the missed metabolic acid-base disturbances. They found that in $14 \%$ of the samples when the anion gap was corrected for hypoalbuminemia, the hidden abnormalities became manifest. Overall, Stewart's and corrected anion gap approaches gave close in their diagnostic ability and there was a good correlation between the anion gap and SIG. ${ }^{11}$

While these studies have shown an exceptionally high degree of correlation of anion gap and SIG, however in our study the correlation was only moderate, which may have been due to potential differences in patient population, illness severity, or pathology.

Chaiyakulsil et al. obtained 1,338-paired measures from 130 critically ill pediatric patients over a 2-year period. They excluded 
the samples with acid-base disturbances due to respiratory causes and evaluated the remaining 743-paired samples as a metabolic subgroup. They looked at the correlation between various parameters obtained from Stewart's approach (such as SID, SIG, SIDa, and SIDe) and the traditional bicarbonate and base excess parameters approach to the $\mathrm{pH}$ of the ABG. Of all parameters, the SIDe (effective strong ion difference) showed the greatest correlation with the $\mathrm{pH}$. Among the traditional approaches, standard base excess showed the best correlation with the $\mathrm{pH}$. The authors suggested that for purpose of simplification simple $\mathrm{SID}$ and $\mathrm{Na}-\mathrm{Cl}$ gap be used for screening of metabolic disorders at the bedside. ${ }^{16}$

The strength of this study was that we measured all the parameters (except sulfate) used in Stewart's calculator, to obtain accurate results. The critically ill patients had severe derangements in albumin and metabolic state where a holistic approach like Stewarts was expected to perform better at picking up missed disorders.

A limitation of this study is that it was a single-center study, conducted on a highly specific group of patients with malignancy. Thus, the results may have limited external validity and generalizability. In this study, the normal reference ranges of parameters in the patient population were taken as well accepted textbook values and not determined from blood samples of healthy volunteers representative of the study population.

Another potential weakness of this study was the use of multiple blood gas samples from the same patient over the duration of their ICU stay. This may lead to over or underestimation of the effect size due to the potential correlation of results within an individual patient. This was given due consideration whilst designing the study: it was considered that the nature of acid-base status in critically unwell patients being dynamic, each individual ABG would represent a new equilibrium state. An additional limitation of our study was that we did not perform a formal sample size calculation, since there is a lack of data about how many missed abnormalities will be picked up using Stewart's approach as compared to the traditional methods.

A limitation of the Stewart's approach methodology is that although the calculator can quantify the relative contributions of the three independent factors to the overall acid-base situation, it does not indicate whether a process is primary or compensatory as this often requires a medical history, examination, investigations, and analysis, hence comparison of results were restricted to analysis of metabolic derangements.

We did not suggest that any interventions be performed based on the interpretation of the $A B G$ data to the clinicians looking after the patients since this was an observational study. The blood gas results were also not sequentially analyzed to see the effect of treatment being administered.

We also did not document the ICU or hospital outcomes. In any case, none of the previous studies have shown any prognostic advantages of Stewart's approach over the traditional approaches. $^{16-21}$

\section{ConcLusion}

In this study, we found that the acAnion Gap approach was similar in diagnostic performance to Stewart's approach in detecting missed acid-base disorders. We feel that the corrected anion gap approach can be safely used if a ready calculator for Stewart's approach is not available. It remains unclear how treating the additional anomalies diagnosed by Stewart's approach will affect the patient outcomes. Future studies should evaluate the effect of treatment directed towards additional anomalies picked up using Stewart's approach and patient outcomes.

\section{Supplementary Material}

All the supplementary material from Supplementary 1-6 tables are available online on the website of www.IJCCM.org.

\section{ORCID}

Rohit Paliwal (1) https://orcid.org/0000-0002-1005-6222

Adrian Pakavakis @ https://orcid.org/0000-0003-0527-5348

Jigeeshu V Divatia ำ https://orcid.org/0000-0001-7384-4886

Atul P Kulkarni @ https://orcid.org/0000-0002-5172-7619

\section{References}

1. Narins RG, Emmett M. Simple and mixed acid-base disorders: a practical approach. Medicine (Baltimore) 1980;59(3):161-187. DOI: 10.1097/00005792-198005000-00001.

2. Emmet M, Narins RG. Clinical use of anion gap. Medicine (Baltimore) 1977;56(1):38-54. PMID: 401925

3. Figge J, Jabor A, Kazda A, Fencl V. Anion gap and hypoproteinemia. Crit Care Med 1998;26(11):1807-1810. DOI: 10.1097/00003246$199811000-00019$.

4. Durward A, Mayer A, Skellett S, Taylor D, Hanna S, Tibby SM, et al. Hypoalbuminaemia in critically ill children: Incidence, prognosis, and influence on the anion gap. Arch Dis Child 2003;88(5):419-422. DOI: $10.1136 /$ adc.88.5.419.

5. Stewart PA. Modern quantitative acid-base chemistry. Can J Physiol Pharmacol 1983;61(12):1444-1461. DOI: 10.1139/y83-207.

6. Van Slyke DD, Hastings AB, Hiller A, Sendroy J Jr. Studies of gas and electrolyte equilibria in blood: XIV. Amounts of alkali bound by serum albumin and globulin. J Biol Chem 1928;79:769-780. DOI: 10.1016/ S0021-9258(20)79962-X.

7. Figge J, Rossing TH, Fencl V. The role of serum proteins in acid-base equilibria. J Lab Clin Med 1991;117(6):453-467. PMID: 2045713.

8. Fencl V, Rossing TH. Acid-Base disorders in critical care medicine. Annu Rev Med 1989;40:17-29. DOI: 10.1146/annurev.me.40.020189.000313.

9. Cook L, Macdonald DH. Management of paraproteinaemia. Postgrad Med J 2007;83(978):217-223. DOI: 10.1136/pgmj.2006.054627.

10. Dubin A, Menises MM, Masevicius FD, Moseinco MC, Kutscherauer DO, Ventrice $E$, et al. Comparison of three different methods of evaluation of metabolic acid-base disorders. Crit Care Med 2007;35(5):1264-1270. DOI: 10.1097/01.CCM.0000259536.11943.90.

11. Fencl V, Jabor A, Kazda A, Figge J. Diagnosis of metabolic acid-base disturbances in critically ill patients. Am J Respir Crit Care Med 2000;162(6):2246-2251. DOI: 10.1164/ajrccm.162.6.9904099.

12. Murray T, Long W, Narins RG. Multiple myeloma and the anion gap. N Engl J Med 1975;292(11):574-575. DOI: 10.1056/ NEJM197503132921107.

13. O'Connor DT, Stone RA. Hyperchloremia and negative anion gap associated with polymyxin B administration. Arch Intern Med 1978;138(3):478-480. PMID: 204265.

14. Bland JM, Altman DG. Statistical methods for assessing agreement between two methods of clinical measurement. Lancet 1986;1(8476):307-310. PMID: 2868172.

15. McAuliffe JJ, Lind LJ, Leith DE, Fencl V. Hypoproteinemic alkalosis. Am J Med 1986;81(1):86-90. DOI: 10.1016/0002-9343(86)90187-7.

16. Chaiyakulsil C, Mueanpaopong $P$, Lertbunrian $R$, Chutipongtanate $S$ Connecting two worlds: positive correlation between physicochemical approach with blood gases and $\mathrm{pH}$ in pediatric ICU setting. BMC Res Notes 2019;12(1):742. DOI: 10.1186/s13104-019-4770-6.

17. Wilkes P.Hypoproteinemia, strong-ion difference, and acid-base status in critically ill patients. J Appl Physiol (1985) 1998;84(5):1740-1748. DOI: 10.1152/jappl.1998.84.5.1740. 
18. Kaplan LJ, Kellum JA. Initial pH, base deficit, lactate, anion gap, strong ion difference, and strong ion gap predict outcome from major vascular injury. Crit Care Med 2004;32(5):1120-1124. DOI: 10.1097/01.ccm.0000125517.28517.74.

19. Dondorp AM, Chau TT, Phu NH, Mai NT, Loc PP, Chuong LV, et al. Unidentified acids of strong prognostic significance in severe malaria. Crit Care Med 2004;32(8):1683-1688. DOI: 10.1097/01. ccm.0000132901.86681.ca.
20. Cusack RJ, Rhodes A, Lochhead P, Jordan B, Perry S, Ball JA, et al The strong ion gap does not have prognostic value in critically ill patients in a mixed medical/surgical adult ICU. Intensive Care Med 2002;28(7):864-869. DOI: 10.1007/s00134-002-1318-2.

21. Carreira F, Anderson RJ. Assessing metabolic acidosis in the intensive care unit: does the method make a difference? Crit Care Med 2004;32(5):1227-1228. DOI: 10.1097/01.ccm.0000125513. 26170.d2. 


\section{Appendix}

\section{Appendix 1: The Calculator for ABG Analysis with Stewart's Approach}

Ready Excel spreadsheet calculator (Acid-Base Calculator V10.8.xls from Dr Peter Lloyd of Hawke's Bay Hospital, Hasting, New Zealand) was used for the interpretation of the blood gas with Stewart's approach.

This was a free public access download from the website acidbase.org where it was made available by Dr Ross Freebairn (the Medical Director for Intensive Care Services at Hawke's Bay Hospital, Hasting, New Zealand).

The calculator accepts laboratory data as inputs and displays a report, which quantifies the three independent parameters that are known to control acidity. These parameters are the SID, which summarizes the strong or fully dissociated electrolytes, the total weak acid concentration (Atot-), which summarizes the nonvolatile weak or partially dissociated electrolytes, and the partial pressure of carbon dioxide $\left(\mathrm{PCO}_{2}\right)$.
It quantifies the three independent factors that control acidity calculates the concentration and charge of unmeasured ions, and displays graphically the value of the independent factors, the predicted acidity, the measured acidity, and the net concentration of unmeasured ions. Thus, it produces a report based on these calculations and displays a Gamblegram depicting measured ionic species.

The minimum data set required is $\mathrm{pH}, \mathrm{PCO}_{2},[\mathrm{Na}]^{+1},[\mathrm{~K}]^{+1},[\mathrm{Cl}]^{-1}$, but it also takes protein, phosphate, hemoglobin, urea, uric acid, sulfate, and other ionic concentrations.

The strong ion calculator takes the concentrations of the measured strong electrolytes (and in the case of calcium and magnesium converts the concentration into ionic strength). The only strong ion that is not routinely available for analysis in modern medical laboratories is sulfate. Its concentration can increase greatly in renal failure. 
Appendix 2: Data Entry Page for the Spreadsheet Calculator

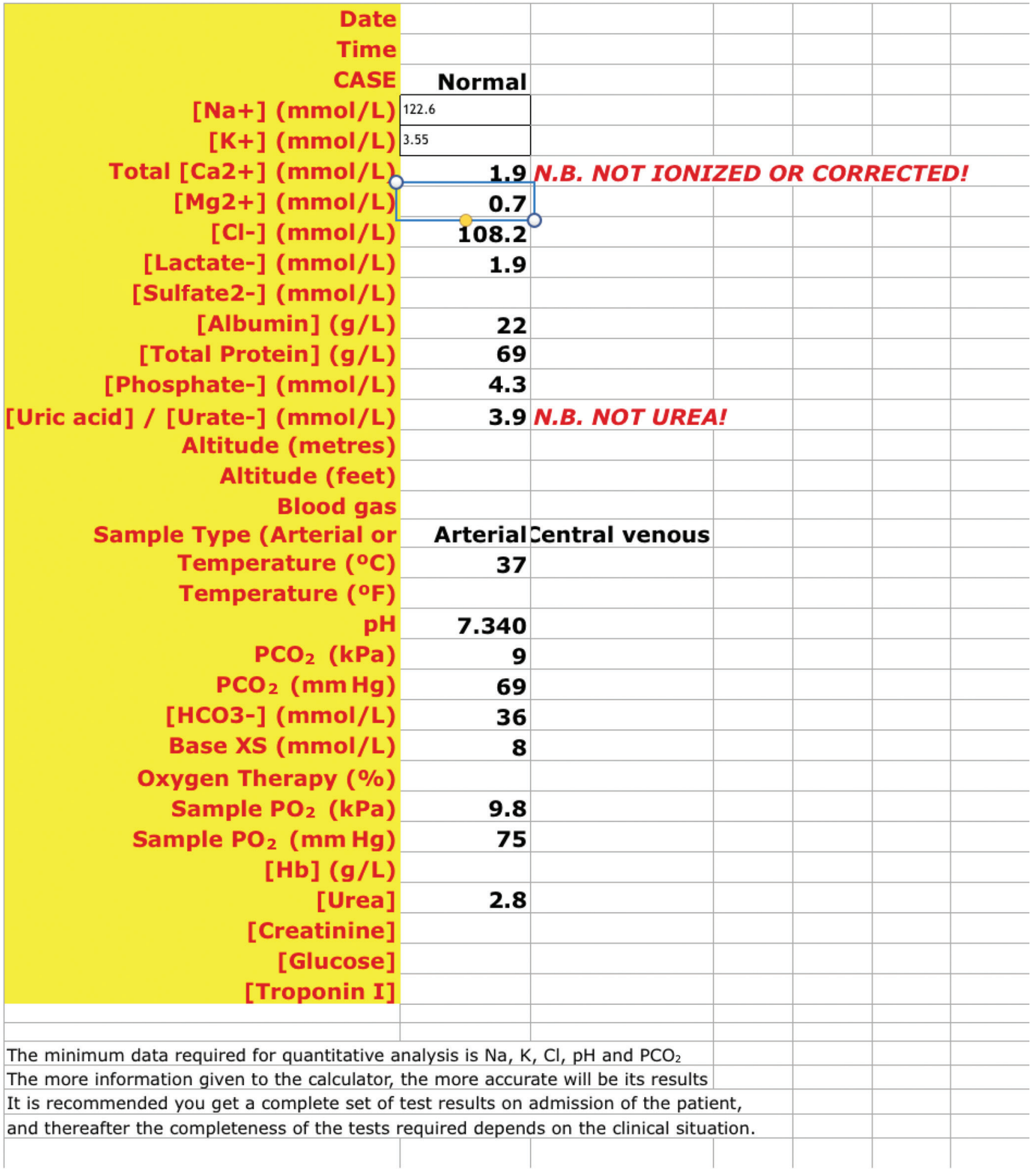


Appendix 3: Example of Report Obtained from the Spreadsheet Calculator

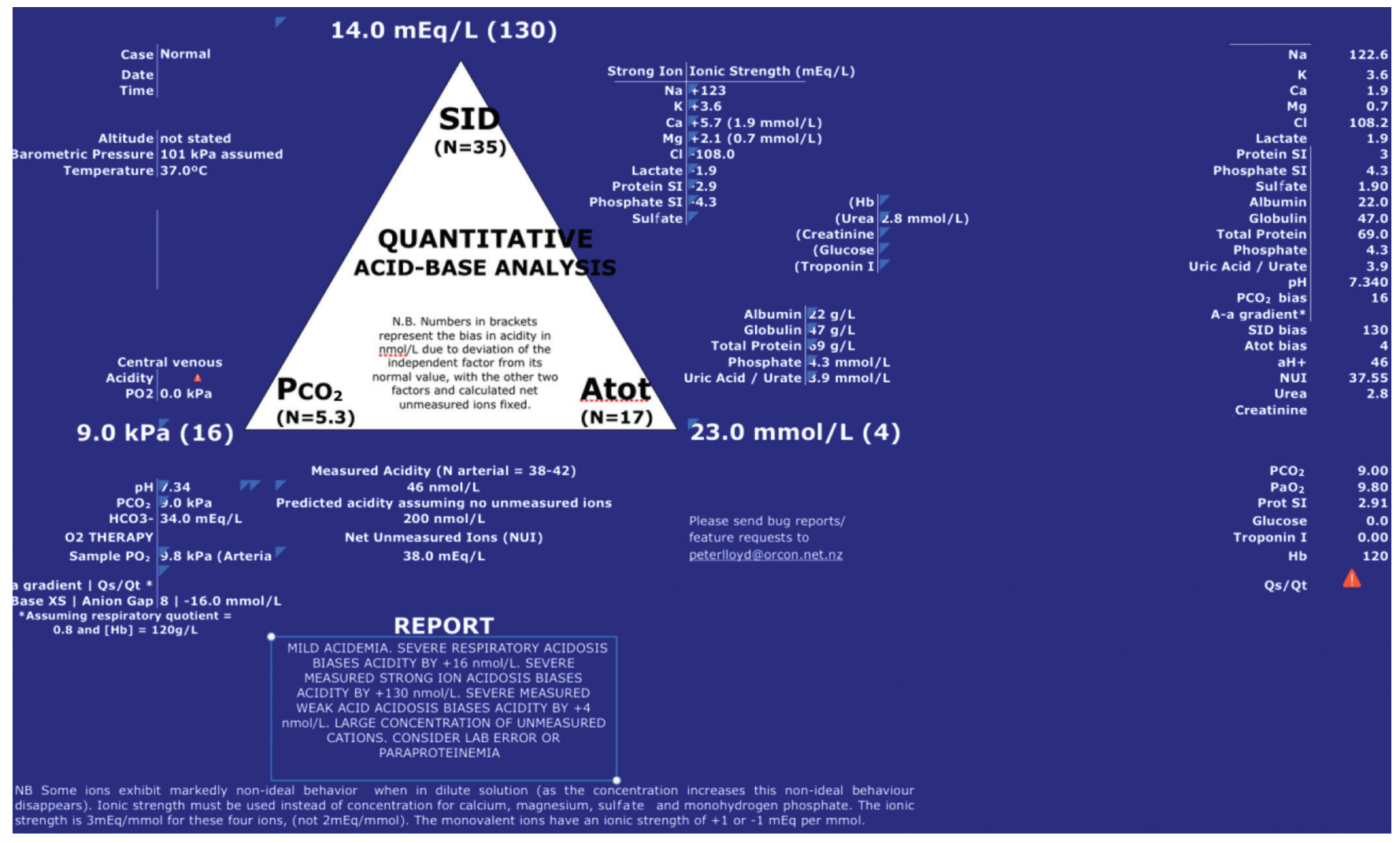

The values of the three independent parameters are displayed at each corner of a triangle. The direction and degree to which variation of each parameter individually affects the acidity are displayed in brackets. The individual results that contributed to the calculation of the independent parameters are tabulated nearby.

Beneath this is a printed report box and the gamblegram for the patient.

\section{Report Box}

\section{REPORT}

MILD ACIDEMIA. SEVERE RESPIRATORY ACIDOSIS BIASES ACIDITY BY $+17 \mathrm{nmol} / \mathrm{L}$. SEVERE MEASURED STRONG ION ALKALOSIS BIASES ACIDITY BY -27 nmol/L. NORMAL MEASURED Atot. DEVIATION FROM $17 \mathrm{mmol} / \mathrm{L}$ BIASES ACIDITY BY 0 $\mathrm{nmol} / \mathrm{L}$. MODERATE CONCENTRATION OF UNMEASURED ANIONS INDICATES MODERATE UNMEASURED COMPONENT OF METABOLIC ACIDOSIS 


\section{Gamblegram}

Gamblegram has two bars, one depicting the concentration of cations, the other anions.

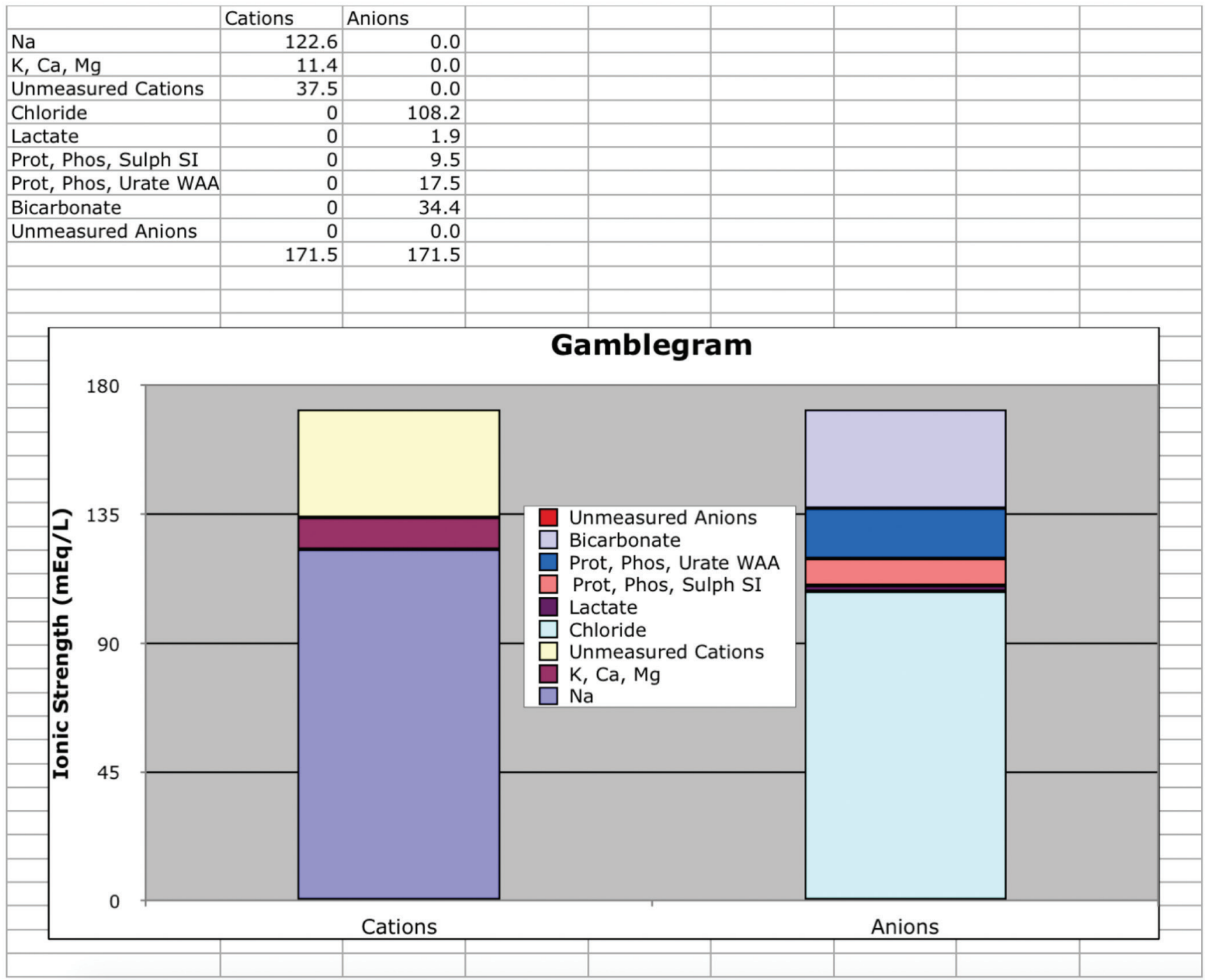

Strong ions are fully dissociated throughout the physiological range of acidity. The weak acid anions (bicarbonate, proteins, phosphate) must change their equilibrium concentrations to conform to the space available (the SID). Otherwise, the solution would violate the requirement that at equilibrium the cations are opposed by an equal concentration of anions. 